\title{
LAW ON THE ELECTRONIC FRONTIER
}





\section{THE DAVID HUME INSTITUTE}

Hume Papers on Public Policy

Volume 2 No 4 Winter 1994

\section{LAW ON THE ELECTRONIC FRONTIER}

Ian J Lloyd and Moira Simpson

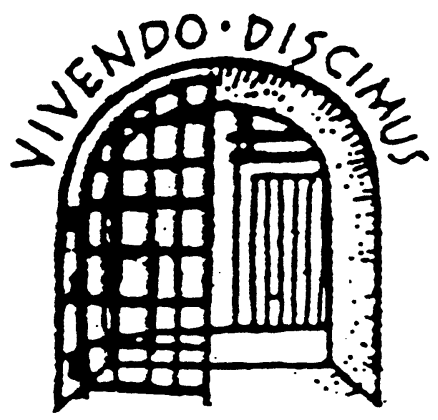


C David Hume Institute 1994

Edinburgh University Press

22 George Square, Edinburgh

Transferred to digital print 2008

Typeset in Times New Roman by ROM-Data Corporation Ltd., Falmouth, Cornwall and printed and bound in Great Britain by CPI Antony Rowe, Eastbourne, East Sussex

A CIP record for this book is available from the British Library

ISBN 0748605940 